\title{
Biology of Zygogramma bicolorata Pallister on Parthenium hysterophorus Linn. under Laboratory Conditions
}

\author{
Ajaya Shree Ratna Bajracharya ${ }^{1 *}$, Resham Bahadur Thapa ${ }^{2}$, Gopal Bahadur KC ${ }^{2}$, \\ Shree Baba Pradhan ${ }^{1}$ and Jagat Devi Ranjit ${ }^{3}$
}

\author{
${ }^{\prime}$ National Entomology Research Center, Khumaltar, Lalitpur, Nepal \\ ${ }^{2}$ Institute of Agriculture and Animal Science, Tribhuwan University, Nepal \\ ${ }^{3}$ National Agronomy Research Center, Khumaltar, Lalitpur, Nepal
}

\section{*CORRESPONDENCE:}

Ajaya Shree Ratna Bajracharya

National Entomology Research Center,

Khumaltar, Lalitpur, Nepal

Email: ajayabajracharya@yahoo.com

ISSN : 2382-5359(Online), 1994-1412(Print)

DOI:

https://doi.org/10.3126/njst.v20i1.39375

\section{ACCESS THE ARTICLE ONLINE}

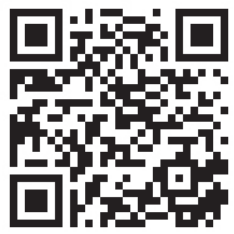

\section{CONFILICT OF INTEREST: None}

Copyright: The Author(s) 2020. This is an open access article under the $\mathrm{CC} \mathrm{BY}$ license.

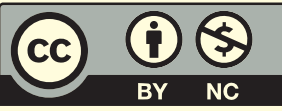

\begin{abstract}
Parthenium hysterophorus Linn. is one of the most aggressive, invasive weeds threatening natural and agricultural ecosystems in the world including Nepal. Augmentative release of host-specific, leaf feeding beetle, Zygogramma bicolorata Pallister (Coleoptera: Chrysomelidae) is one of the sustainable management approaches of parthenium weed. Successful mass rearing program requires knowledge on biology of $Z$. bicolorata for augmentative release. Thus, life cycle and biology of $Z$. bicolorata were studied in lab at $26 \pm 2{ }^{\circ} \mathrm{C}$ temperature and $70 \pm 10 \%$ relative humidity at NARC, Lalitpur, Nepal during March to September, 2016. The average incubation, larval and pupal periods of the insect were $4.33,12.20$, and 11.00 days, respectively. A single female could lay 1,837 eggs in 58.80 days oviposition period with $73.01 \%$ egg hatchability. The insect completed its life cycle in 108.40 and 105.50 days with adult longevity of 91.90 and 75.00 days for females and males, respectively. The average length of egg, pupa, adult female and male was $1.19 \mathrm{~mm}, 5.90 \mathrm{~mm}, 6.58 \mathrm{~mm}$ and $5.32 \mathrm{~mm}$ and breadth $0.51 \mathrm{~mm}, 3.74 \mathrm{~mm}, 3.94 \mathrm{~mm}$ and $3.20 \mathrm{~mm}$, respectively. The average lengths of the first, second, third and fourth instar larvae were found $1.30 \mathrm{~mm}, 3.02 \mathrm{~mm}, 4.96 \mathrm{~mm}$ and $8.08 \mathrm{~mm}$ and breadth of $0.44 \mathrm{~mm}, 1.13 \mathrm{~mm}, 2.02 \mathrm{~mm}$ and $3.16 \mathrm{~mm}$, respectively. These findings will help in mass multiplication of $Z$. bicolorata for biological control of parthenium weed.
\end{abstract}

Keywords: Mexican beetle, parthenium, life cycle, head capsule, instars and oviposition period.

\section{INTRODUCTION}

Parthenium hysterophorus L. (Asteraceae; Heliantheae), commonly known as parthenium, is an annual or short-lived perennial, herbaceous plant. Parthenium is a noxious, invasive weed of both agricultural and natural ecosystems (Shrestha et al. 2019). It is a weed of global significance, which causes losses in agriculture, adverse effects on human and animal health and degrades natural ecosystems (Kaur et al. 2014). This weed has characteristics of prolific nature producing up to 25,000 viable seeds per plant (Shrestha et al. 2019). The weed is native to tropical America and is problematic in tropical and subtropical regions of the world. It has been spread into 96 countries of Africa, Asia, Europe, North 
America, Oceania and South America (CABI 2020a). The weed entered India from the United States of America along with wheat imported into Pune during 1956 (Vertak 1968). It is suspected that parthenium entered Nepal from India along with vehicles or contaminated seeds, in 1960s (Mishra 1991). The significant expansion of parthenium occurred in Nepal during 1990 (Shrestha et al. 2015). Presently, this weed has been found in terai, mid hill and high hill regions reaching up to the altitude of 2,000 $\mathrm{m}$ asl (Shrestha et al. 2019).

Parthenium can be managed through physical, chemical and biological approaches. Biological control with insects is one of the most important approaches used in the sustainable management of the weed (Adkins \& Shabbir 2014). Nine host-specific insect species were introduced in Australia, including Z. bicolorata (Adkins \& Shabbir 2014). Learning from successful biological control of parthenium weed in Australia, Z. bicolorata was released in Bangalore, India in 1984 (Jayant 1987). There is no record of the deliberate introduction and release of $Z$. bicolorata in Nepal, but it fortuitously arrived from India and spread into various parts of Nepal (Shrestha et al. 2010; Shrestha et al. 2011).

The beetle, Z. bicolorata, is commonly known as the Mexican beetle, but also called as parthenium beetle (CABI 2020b). Larval and adult feeding on parthenium results in skeletonization, defoliation and reduction in flowers and seed production. $Z$ bicolorata can cause $100 \%$ defoliation of parthenium, resulting in reduced weed density, plant height, plant biomass, flower production and soil seed bank (Dhileepan et al. 2000). Augmentative release of $Z$. bicolorata is one of the sustainable management approaches of pernicious weed $P$. hysterophorus. However, several augmentative releases may be required to ensure the establishment and effective control of parthenium (Sushilkumar \& Ray 2011). Successful mass rearing technology is needed for an effective augmentative release program of $Z$. bicolorata against parthenium weed. Knowledge of the life cycle and biology of $Z$. bicolorata is indispensable to initiate any mass rearing and augmentative release program. Hence, the present study was undertaken to understand the life cycle and biology of $Z$. bicolorata under lab conditions.

\section{MATERIALS AND METHODS}

Studies were conducted in the laboratory of National Entomology Research Center, Nepal Agricultural Research Council, Khumaltar, Lalitpur, Nepal. A temperature of $26 \pm 2{ }^{\circ} \mathrm{C}$ and relative humidity of $70 \pm 10 \%$, were maintained in the laboratory with the help of air conditioner and humidifier, respectively. The average monthly temperature and relative humidity during the study period are presented in Fig. 1.

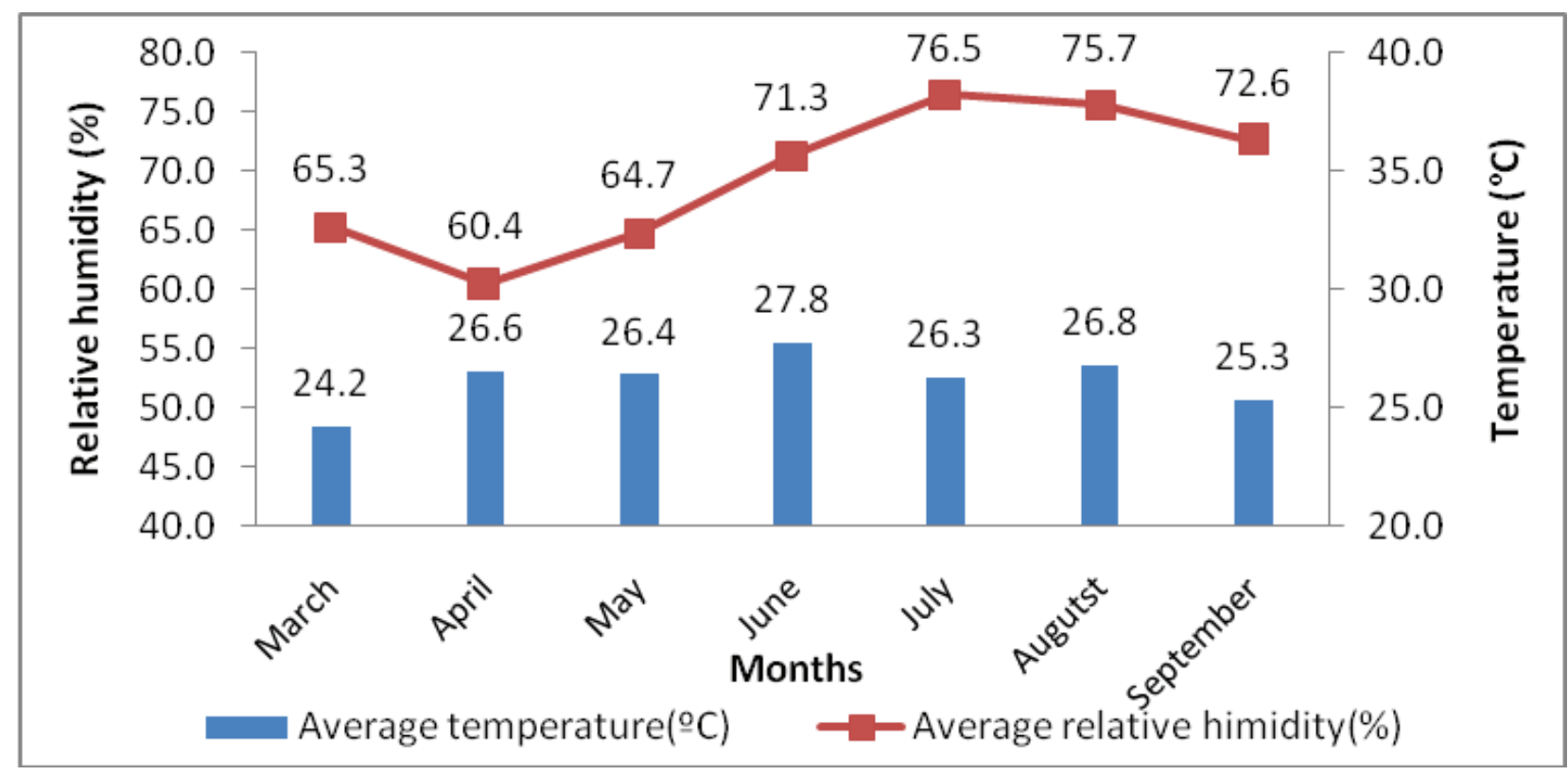

Fig. 1. Average monthly temperature and relative humidity in the laboratory during the study period 


\subsection{Culture of Z. bicolorata}

Adult males and females of Z. bicolorata were collected from Khageri irrigation dam site (N 02734.110', E 084 $43.792^{\prime}$ ') of Chitwan district. The insects were reared in rectangular plastic boxes of $22.7 \mathrm{~cm} \mathrm{X} 16.3 \mathrm{~cm} \mathrm{X} 9.0$ $\mathrm{cm}$ length, breadth, and height, respectively. (Fig. 2a). Ventilation was provided in boxes by cutting holes of 10 $\mathrm{cm}$ X $5 \mathrm{~cm}$ dimensions on lid, which was made insect proof with a black muslin cloth. Bouquets of fresh parthenium leaves with few flowers (Fig. 2b) were provided as food for adults and larvae of $\mathrm{Z}$. bicolorata. Cut ends of leaves were covered with moistened cotton and wrapped with aluminium foil to delay drying. The bouquets of leaves were changed daily in rearing cages after cleaning, and $Z$. bicolorata larvae and adults attached to old leaves were transferred back with the help of a camel hair brush. Eggs laid on leaves and black muslin cloth of window in rearing

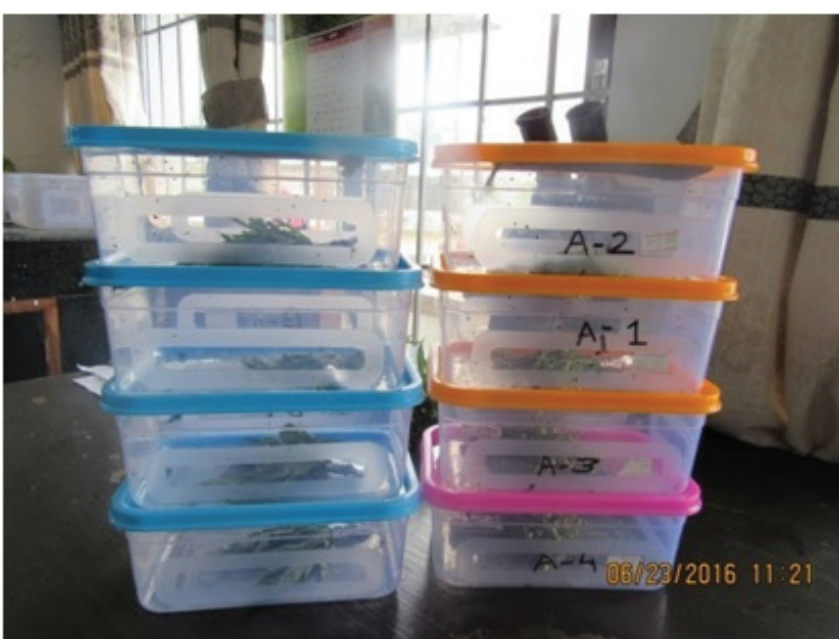

Fig. 2. (a) Experimental set up in plastic cages, (b) Bouquets of fresh Parthenium leaves with flowers

\subsection{Life cycle and biology}

The life cycle and biology of $Z$. bicolorata were studied in laboratory conditions at $26 \pm 2{ }^{\circ} \mathrm{C}$ average temperature and $70 \pm 10 \%$ average relative humidity during March to September, 2016. Newly laid eggs were used for the study of developmental periods of immature stages. Eggs were kept in a $9 \mathrm{~cm}$ diameter Petri plate to determine the incubation period (duration between egg laying and hatching). Newly hatched, first instar larvae were transferred individually into $9 \mathrm{~cm}$ Petri plates, and fresh parthenium leaves were provided as food. Completely randomized design (CRD) was followed and 30 replications were maintained. Moulting and duration of larval instars were recorded daily, and parthenium leaves were also changed daily. Prepupa were transferred individually into pupation cages

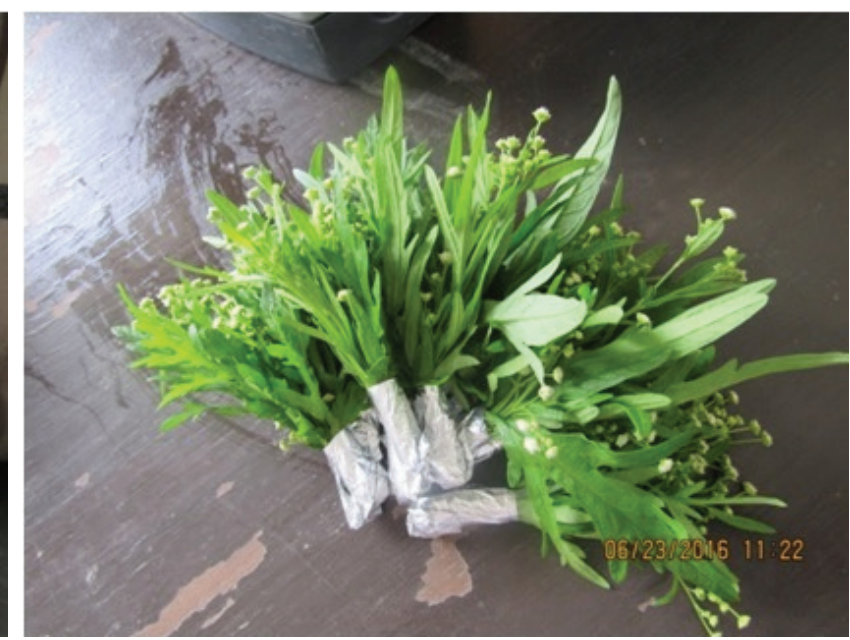

boxes were collected with a camel hair brush and further used to multiply the insect. The eggs were kept in a $9 \mathrm{~cm}$ Petri plate and first instar larvae immediately after hatching were transferred into plastic, rearing cages along with bouquets of parthenium leaves. Pupation cages were made of plastic rearing boxes with $5 \mathrm{~cm}$ depth of soil as pupation media. Pupation media were prepared from field-collected soil and sand mixed in a 1:1 ratio. Medium was sterilized in a hot air oven at $80^{\circ} \mathrm{C}$ for 30 minutes, and distilled water was sprinkled to maintain soil moisture. When the larvae stopped feeding and became pre-pupa, fully grown larvae, were transferred into pupation cages, and moisture in soil was maintained by regularly sprinkling distilled water on the soil surface. Newly emerged adults of $Z$. bicolorata were again transferred into plastic rearing cages with parthenium leaves for mating and further multiplication.

made of plastic boxes of $18.7 \mathrm{~cm} \mathrm{X} 12.6 \mathrm{~cm} \mathrm{X} 7.8 \mathrm{~cm}$ length, breadth, and height, respectively. The pupation period was recorded as the time between dates of pupation to adult emergence.

Thirty pairs of newly emerged adults were used to determine pre-oviposition, oviposition and post-oviposition periods, longevity of adult females and males and egg-laying capacity of $Z$. bicolorata. Pair of adults were individually kept in plastic rearing cages of size $18.7 \mathrm{~cm} \mathrm{X} 12.6 \mathrm{~cm}$ $\mathrm{X} 7.8 \mathrm{~cm}$ length, breadth, and height, respectively, with the provision of ventilation. Parthenium leaf bouquets were provided as adult food. The daily observation on initiation of egg laying, number of eggs laid by each pair and cessation of egg laying, and live and dead adults was recorded on the number of eggs laid. The pre-oviposition 
period of an adult female was determined as the time between the date of adult emergence and initiation of egglaying. Similarly, the oviposition period was recorded as the time between the initiation and cessation of egg-laying. Post-oviposition period was recorded as the duration of adult female survival after cessation of egg-laying. The date of male and female adults' death was recorded to calculate adult longevity.

Twenty different clusters of eggs were kept separately in $9 \mathrm{~cm}$ Petri-plates to determine the hatching percentage. On an average, each cluster consisted of 57 eggs (ranging from $42-80$ eggs). Number of eggs hatched each day were counted and the average hatching percentage was calculated. Similarly, pupae were collected daily from Z. bicolorata rearing and were kept in separate pupation boxes for 20 days during June, 2016. Emergence of adult males and females was recorded daily. Percent adult emergence, percent male and female adults' emergence were calculated.

Length and breadth of immature and mature life stages (egg, larva, pupa \& adults) of Z. bicolorata were measured with the help of an ocular micrometer in a stereomicroscope

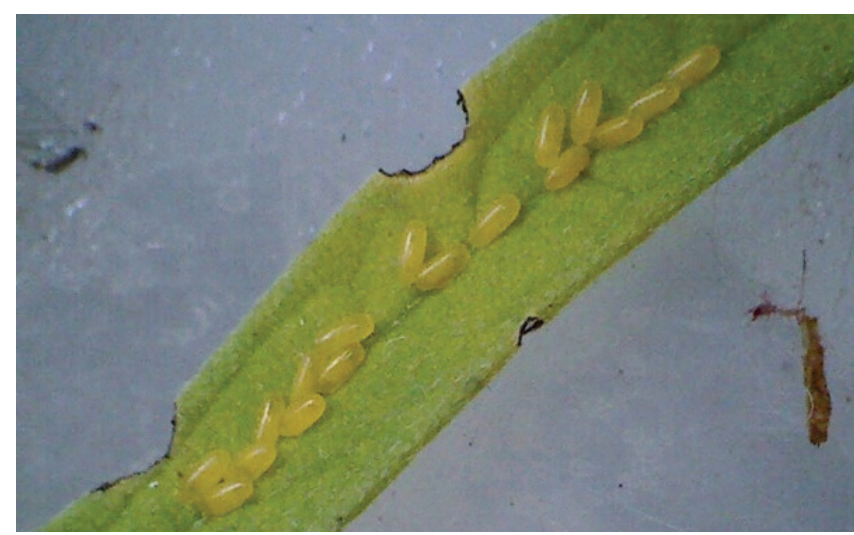

(a)

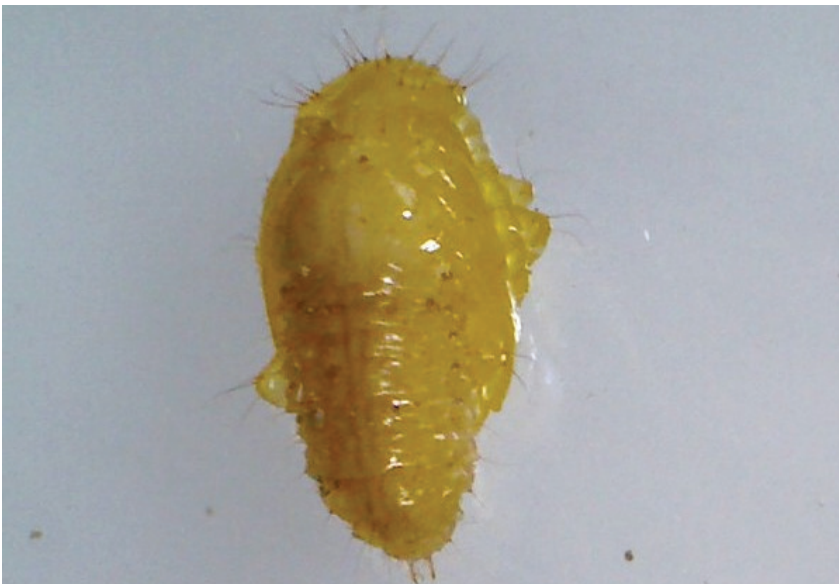

(c)
(Bestscope BS-3040T). The ocular micrometer was calibrated with the stage micrometer of one-millimetre size (ERMA INC. Japan) at the observed level of magnification. Length and breadth of egg, larvae, pupae and adult moths were measured. Head capsule widths from larval exuviae of all larval instars were also measured. Similarly, the weight of all immature and mature stages of Z. bicolorata was measured with digital balance (Sartorius ENTRIS2241-1S). Weight of five first instar larvae were measured at a time due to the small size, and weight of one larva was calculated. Similarly, two larvae were taken for second instar larvae. Data obtained from observations were entered into Microsoft excel, and the mean values, ranges and standard error of the mean were calculated using statistical program Genstat Discovery Edition 4.

\section{RESULTS AND DISCUSSION}

\subsection{Life cycle of $Z$. bicolorata}

The beetle $Z$. bicolorata consisted of four life stages viz., egg, larva, pupa and adult with complete metamorphosis (Fig. 3a-d). The duration of various life stages of the insect is presented in Table 1 .

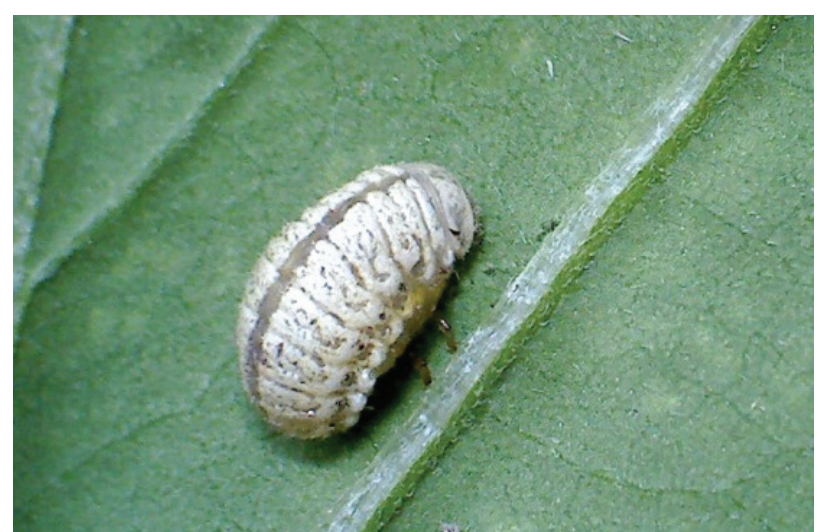

(b)

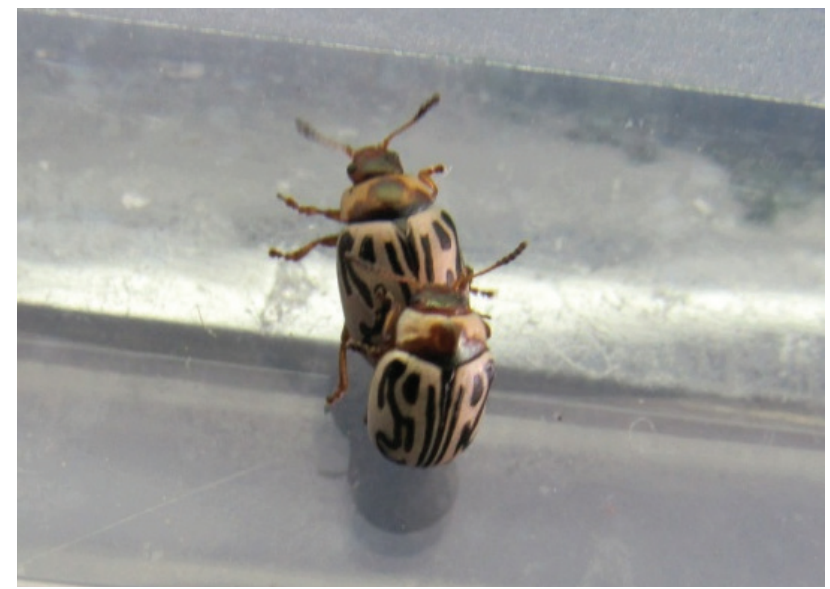

(d)

Fig. 3. Different developmental stages of Z. bicolorata, (a) Egg, (b) Larva, (c) Pupa and (d) Adults 
Eggs were generally laid singly or in a cluster of 2-5 on the leaf surface or muslin cloth on the lid of rearing boxes. Eggs were oblong in shape and light yellow with a smooth surface that turned into dark yellow before hatching. The average incubation period of an egg was found 4.33 days ranging from 4 - 5 days. The larva of the insect consisted of four instars and moulted three times before pupation. The newly hatched larva was pale yellow which turned into creamy white as it grew. The first and second instar larvae were similar in appearance except in size, whereas, third and fourth instars were similar in appearance, and black coloured spiracles were visible on the abdomen and on lateral sides of thorax. The larvae were slightly curved with a protrusible proleg-like structure at the posterior end for locomotion. Larval duration of first, second, third and fourth instars was 3.33, 2.33, 2.13, and 4.40 days, respectively. The mean larval period was 12.20 days ranging from 11-14 days.

Pupation took in the soil about 1-2 cm deep in the pupal cage in the laboratory. The pupae were of exarate type and off-white to pale yellow in color. The pupal period was 11 days ranging from 10-12 days. The total developmental period of the immature stages was found 27.53 days ranging from 25-30 days. Various previous workers also reported similar duration of developmental period of egg, larva and pupa (Jayanth \& Bali 1993; Pandey et al. 2001; Dhiman \& Bhargawa 2005; Sidhapara et al. 2012; Rathod et al. 2012; Mehata \& Raghuraman 2019).

Table 1. Duration of various developmental stages of $Z$. bicolorata under lab conditions.

\begin{tabular}{|l|c|c|}
\hline \multicolumn{1}{|c|}{ Stages } & Mean (days) & Range (days) \\
\hline Egg (incubation period) & $4.33 \pm 0.088^{*}$ & $4-5$ \\
\hline First larval instar & $3.33 \pm 0.088$ & $3-4$ \\
\hline Second larval instar & $2.33 \pm 0.088$ & $2-3$ \\
\hline Third larval instar & $2.13 \pm 0.063$ & $2-3$ \\
\hline Fourth larval instar & $4.40 \pm 0.123$ & $4-6$ \\
\hline Total larval period & $12.20 \pm 0.147$ & $11-14$ \\
\hline Pupa & $11.00 \pm 0.127$ & $10-12$ \\
\hline Total developmental period & $27.53 \pm 0.243$ & $25-30$ \\
\hline Pre-oviposition period & $10.50 \pm 0.150$ & $9-12$ \\
\hline Oviposition period & $58.80 \pm 2.630$ & $39-96$ \\
\hline Post-oviposition period & $22.60 \pm 1.873$ & $2-49$ \\
\hline Adult female longevity & $91.90 \pm 2.092$ & $57-107$ \\
\hline Adult male longevity & $75.00 \pm 3.571$ & $46-124$ \\
\hline Total life cycle of female & $108.40 \pm 2.062$ & $84-134$ \\
\hline Total life cycle of male & $105.50 \pm 3.584$ & $73-151$ \\
\hline * Standard Error of Mean & \\
\hline
\end{tabular}

Adults emerged from the soil after completion of pupation. Adults were oval, convex dorsally and flat ventrally. Elytra were creamy yellow with black, elongated elytral markings, and the head was black. Average adult female longevity was 91.90 days, ranging from 57-107 days, and adult male longevity was recorded 75 days, ranging from 46-124 days. Adult females were found to survive longer than adult males, such longer female longevity was also reported by previous researchers (Jayanth \& Bali 1993; Mehta \& Raghuraman 2012). Jayanth and Bali (1993) reported adult female and male longevity as 210.00 and 129.30 days, respectively. Siddhapra et al. (2012) found 80.56 days and 85.48 days of adult female and male longevity, respectively, which is quite similar to the present study, though they found adult males survived longer than adult females.

In the present study, the total life cycle was recorded 108.40 days for an adult female, ranging from 84-134 days, and 105.50 days for an adult male, ranging from 73-151 days. Sidhapara et al. (2012) reported a similar total life cycle of Z. bicolorata, i.e., 104.08 days and 109.54 days of adult females and males, respectively. The average oviposition period was found 58.80 days, ranging from 39-96 days. The oviposition period was recorded 53.30 days by Sidhhpara et al. (2012), which was close to the present study. The pre-oviposition and post-oviposition periods in this study were recorded 10.50 days and 22.60 days, respectively. The duration of pre- and post-oviposition periods were similar to the findings of Sidhhapar et al. (2012) (8.68 days \& 18.58 days) and Mehta and Raghuraman (2019) (8.59 days $\& 18.35$ days, respectively).

\subsection{Hatching and adult emergence}

The average number of eggs laid by a pair of $Z$. bicolorata, hatching percentage, adult emergence and sex ratio of emerged adults are presented in Table 2. A female laid 1,837 eggs on an average during its life, which ranged from 1,229-2,489 eggs. Previous workers had reported different average fecundity in female $Z$. bicolorata ranging from 663.5 eggs per female (Mehta \& Raghuraman 2019) to 2,520.9 eggs per female (Jayanth \& Bali 1993) during its lifetime. The hatching percentage of the egg was found $73.01 \%$ ranging from $62.50-83.78 \%$. A similar hatching percentage of 66.82 to 78.72 in laboratory was reported by previous workers (Rathod et al. 2012; Sidhhapara et 
al. 2012; Mehta \& Raghuraman 2019). Adults' emergence from pupa in the present experiment was $75.50 \%$. Among the emerged adults, $60.53 \%$ were female, and $39.47 \%$ male with an average sex ratio of 1:1.55 (male:female). Previous workers also reported higher adult female emergence with male to the female sex ratio of 1:1.29 (Sidhhapara et al. 2012) and 1:1.35 (Mehta \& Raghuraman 2019).

Table 2. Egg laying, hatching and adult emergence of $Z$. bicolorata in laboratory

\begin{tabular}{|l|c|c|}
\hline \multicolumn{1}{c}{ Stages } & Mean (days) & Range (days) \\
\hline Total eggs laid, no. & $1837 \pm 106.9 *$ & $1229-2489$ \\
\hline Egg hatching, \% & $73.01 \pm 4.628$ & $62.50-83.78$ \\
\hline Adult emergence, \% & $75.50 \pm 1.754$ & $57.78-89.09$ \\
\hline Adult fe-male emergence, \% & $60.53 \pm 0.711$ & $53.85-68.89$ \\
\hline Adult male emergence, \% & $39.47 \pm 0.711$ & $31.11-46.15$ \\
\hline Average sex ratio & $1: 1.55$ (Male: Female) \\
\hline \multicolumn{3}{|c|}{$*$ Standard Error of Mean } \\
\hline
\end{tabular}

\subsection{Egg-laying capacity of Z. bicolorata}

The average number of eggs laid per week by a single adult female of $Z$. bicolorata during the oviposition period is presented in Fig. 4. The number of eggs laid per week increased up to the third week and decreased from the fourth week onward. The highest number (346 eggs) was laid during the third week of the oviposition period. Eggs laid per week remained above 122 till the $8^{\text {th }}$ week, and scanty after the $10^{\text {th }}$ week of the oviposition period. Pandey et al. (2001) reported that a single female could lay 65 eggs per day during peak production of the oviposition period.

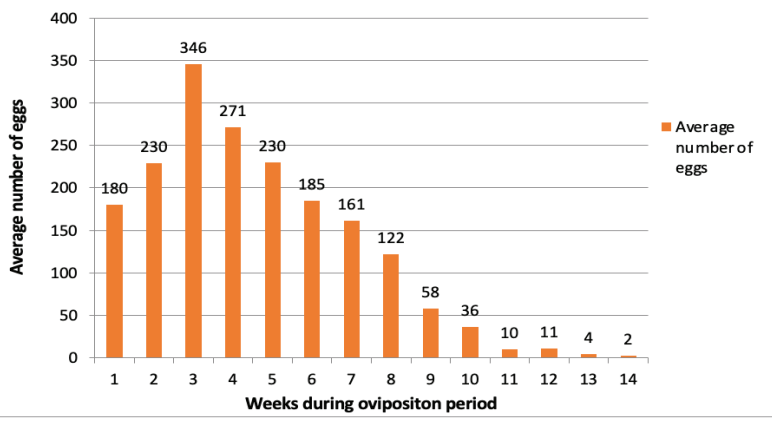

Fig. 4. Egg laying pattern of Z. bicolorata females in laboratory

\subsection{Morphometrics of Z. bicolorata}

Length and breadth of all life stages of live Z. bicolorata, including different instars, were measured with the help of an ocular micrometer (ERMA Inc. Japan) in stereomicroscope (Bestscope BS-3040T). Data obtained are presented in Table 3. The eggs of $Z$. bicolorata were measured $1.19 \mathrm{~mm}$ long and $0.51 \mathrm{~mm}$ wide, and a similar finding was reported by Rathod et al. (2012) (1.22 mm length \& $0.56 \mathrm{~mm}$ width) and Mehta and Raghuraman (2019) (1.33 mm length \& $0.53 \mathrm{~mm}$ width). Similarly, Siddhapra et al. (2012) found Z. bicolorata egg $1.51 \mathrm{~mm}$ long and 0.59 wide, which was a little bit larger than the present finding. Length of the first, second, third and fourth instars larvae was found $1.30 \mathrm{~mm}, 3.02 \mathrm{~mm}, 4.96 \mathrm{~mm}$, and $8.08 \mathrm{~mm}$, respectively. Similarly, breadth was recorded $0.44 \mathrm{~mm}, 1.13 \mathrm{~mm}, 2.02 \mathrm{~mm}$ and $3.16 \mathrm{~mm}$, respectively. Similar measurements were also reported by previous workers (Siddhapara et al. 2012: Dhiman \& Bhargawa, 2005; Mehta \& Raghuraman 2019). Bhusal et al. (2020) reported body size pattern of offsprings of $Z$. bicolorata depended on body size of parents; off springs from larger parents were larger in size.

Table 3. Morphometrics of different life stages of $Z$. bicolorata reared in laboratory.

\begin{tabular}{|l|c|c|c|c|}
\hline \multicolumn{1}{c}{ Life stages } & Length $(\mathbf{m m})$ & Range $(\mathbf{m m})$ & Range (mm) \\
\hline Egg & $1.19 \pm 0.006^{*}$ & $1.13-1.22$ & $0.51 \pm 0.004$ & $0.47-0.53$ \\
\hline First instar larva & $1.30 \pm 0.019$ & $1.10-1.50$ & $0.44 \pm 0.004$ & $1.05 \pm 1.29$ \\
\hline Second instar larva & $3.02 \pm 0.028$ & $2.76-3.33$ & $1.13 \pm 0.011$ & $1.05-1.29$ \\
\hline Third instar larva & $4.96 \pm 0.047$ & $4.38-5.50$ & $2.02 \pm 0.023$ & $3.75-2.25$ \\
\hline Fourth instar larva & $8.08 \pm 0.047$ & $7.50-8.63$ & $3.16 \pm 0.010$ & $3.13-3.25$ \\
\hline Pupa & $5.90 \pm 0.233$ & $5.75-6.25$ & $3.74 \pm 0.011$ & $3.70-3.88$ \\
\hline Adult female & $6.58 \pm 0.039$ & $6.38-7.00$ & $3.94 \pm 0.018$ & $3.13-3.50$ \\
\hline Adult male & $5.32 \pm 0.055$ & $5.00-5.88$ & $3.20 \pm 0.020$ & \\
\hline \multicolumn{5}{|c|}{$*$ Standard Error of Mean } \\
\hline
\end{tabular}


The length of the pupa was recorded as $5.90 \mathrm{~mm}$ and breadth $3.74 \mathrm{~mm}$. Previous workers reported pupal length of $6.18 \mathrm{~mm}$ and width of $3.34 \mathrm{~mm}$ (Mehta \& Raghuraman 2019), whereas $5.65 \mathrm{~mm}$ length and $2.28 \mathrm{~mm}$ breadth were reported by Siddhapara et al. (2012). The length of adult female was $6.58 \mathrm{~mm}$ and width $3.94 \mathrm{~mm}$. Similarly, adult male had length and breadth of $5.32 \mathrm{~mm}$ and 3.20 $\mathrm{mm}$, respectively. Thus, the adult female of $Z$ bicoloratais was larger than the male. The larger size of adult females compared to adult males of $Z$. bicolorata was also reported by previous workers (Jayanth \& Bali 1993; Dhiman \& Bhargawa 2005; Mehta \& Raghuraman 2019). A similar size of adult female (6.21 mm length \& 3.85 width) and male (5.74 $\mathrm{mm}$ length \& $3.61 \mathrm{~mm}$ width) was reported by Jayanth and Bali (1993).

The head capsule was measured from larval exuviae of the first, second and third instars and are presented in Table 4. The widths of head capsule were measured $0.62 \mathrm{~mm}, 0.90$ $\mathrm{mm}$ and $1.34 \mathrm{~mm}$ of the first, second, and third instar larval exuviae. Jayanth and Bali (1993) reported the head capsule size of $0.52 \mathrm{~mm}, 0.80 \mathrm{~mm}$, and $1.08 \mathrm{~mm}$ for the first, second, and third instar larvae, respectively. Similarly, the head capsule was measured $0.56 \mathrm{~mm}, 0.71 \mathrm{~mm}$, and 1.07 $\mathrm{mm}$ for the first, second, and third instars, respectively, by Mehta and Raghuraman (2019).

Table 4. Head capsule width of different instars of $Z$. bicolorata measured from exuviae in laboratory.

\begin{tabular}{|l|c|c|}
\hline \multicolumn{1}{c}{ Larval moults } & Width (mm) & Range (mm) \\
\hline First instar & $0.62 \pm 0.004 *$ & $0.58-0.67$ \\
\hline Second instar & $0.90 \pm 0.003$ & $0.85-0.94$ \\
\hline Third instar & $1.34 \pm 0.008$ & $1.21-1.51$ \\
\hline \multicolumn{3}{|c|}{ * Standard Error of Mean } \\
\hline
\end{tabular}

The average weight of various life stages of $Z$. bicolorata is presented in Table 5. Average larval weight of the first, second, third and fourth instars was recorded $0.24 \mathrm{mg}$, $2.55 \mathrm{mg}, 10.06 \mathrm{mg}$ and $21.00 \mathrm{mg}$, respectively. The weight of the pupa was $29.75 \mathrm{mg}$. Adult female and male weights, immediately after emergence from soil, were $36.17 \mathrm{mg}$ and $25.82 \mathrm{mg}$, which, after one week at the mating stage increased to $43.43 \mathrm{mg}$ and $30.00 \mathrm{mg}$, respectively. The weight of adult females increased to $46.29 \mathrm{mg}$ at the egg laying stage, i.e., 15 days after emergence.
Table 5. Weight of various life stages of $\mathrm{Z}$. bicolorata reared in laboratory.

\begin{tabular}{|l|c|c|}
\hline \multicolumn{1}{|c|}{ Life stages } & Weight (mg) & Range (mg) \\
\hline First instar & $0.24 \pm 0.005 *$ & $0.20-0.28$ \\
\hline Second instar & $2.55 \pm 0.087$ & $1.80-3.60$ \\
\hline Third instar & $10.06 \pm 0.45$ & $7.20-16.30$ \\
\hline Fourth instar & $21.00 \pm 0.74$ & $15.00-29.80$ \\
\hline Pupa & $29.75 \pm 0.602$ & $24.10-36.80$ \\
\hline Newly emerged female & $36.17 \pm 0.54$ & $30.10-41.70$ \\
\hline Female at the mating stage & $43.43 \pm 1.12$ & $32.50-53.20$ \\
\hline Female at egg-laying stage & $46.29 \pm 1.25$ & $33.60-58.10$ \\
\hline Newly emerged male & $25.82 \pm 0.63$ & $20.20-29.90$ \\
\hline Male at the mating stage & $30.00 \pm 0.57$ & $23.20-36.30$ \\
\hline \multicolumn{3}{|c|}{$*$ Standard Error of Mean } \\
\hline
\end{tabular}

\section{CONCLUSION}

The life cycle and biology of Z. bicolorata were studied in the National Entomology Research Center, Khumaltar laboratory Lalitpur, Nepal. Easy mass multiplication of Z. bicolorata feeding with parthenium appeared possible under lab conditions at NARC, Khumaltar. Its average egg incubation, larval and pupal periods appeared to be 4.33, 12.20, and 11.00 days, respectively, whereas, its life cycle was found 108.40 and 105.50 days for females and males, respectively. Present findings on biological parameters of $Z$. bicolorata would help in mass multiplication and release of $Z$. bicolorata for the biological control program of $P$. hysterophorus (parthenium) in Nepal.

\section{ACKNOWLEDGEMENT}

The authors are grateful to the Nepal Agricultural Research Council for providing financial support and laboratory facilities. The technical help from Ms Binu Bhat (Technical Officer) and supports from officials of the National Entomology Research Center and Institute of Agriculture, and Animal Science are highly appreciated.

\section{REFERENCES}

1. Adkins, S. and A. Shabbir. 2014. Biology, ecology and management of the invasive parthenium weed (Parthenium hysterophorus L.). Pest Management Science. 70: 1023-1029.

2. Bhusal, D.R., K.C. Ghimire, R. Upadhyay, M. Bista and B. Kumar. 2020. Phenotypic plasticity along altitudinal gradient affects the feeding efficiency and development of the parthenium beetle, Zygogramma bicolorata (Coleoptera: Chrysomelidae). Acta Entomologica Sinica. 63(9): 1117-1124. 
3. CABI, 2020a. Invasive Species Compendium: Datasheet Parthenium hysterophorus (parthenium weed). https://www.cabi. org/isc/datasheet/45573.

4. CABI, 2020b. Invasive Species Compendium: Datasheet Zygogramma bicolorata (Mexican beetle). https://www.cabi. org/isc/datasheet/57506.

5. Dhileepan, K., S.D. Setter and R.E.C. McFadyen. 2000. Response of the weed Parthenium hysterophorus (Asteraceae) to defoliation by the introduced biocontrol agent Zygogramma bicolorata (Coleoptera: Chrysomelidae). Biological Control. 19: 9-16.

6. Dhiman, S.C. and M.L. Bharghawa. 2005. Biology and population dynamics of Zygogramma bicolorata Pallister: a biocontrol agent of Parthenium hysterophorus Linn. Journal of Applied Zoology and Research. 16(1): 41-43.

7. Jayanth, K.P. 1987. Introduction and establishment of Zygogramma bicolorata on Parthenium hysterophorus at Bangalore, India. Current Science. 56: 310-311.

8. Jayanth, K.P. and G. Bali. 1993. Biological studies on Zygogramma bicolorata Pallister Coleoptera: Chrysomelidae) a biological studies control agent of Parthenium hysterophorus. Journal of Biological Control 7(2):93-98. DOI:10.18311/ JBC/ 1993/15158

9. Kaur, M., N.K. Aggarwal, V. Kumar and R. Dhiman. 2014. Effects and management of Parthenium hysterophorus: A weed of global significance. International Scholarly Research Notices. http:// dx.doi.org/10.1155/2014/368647

10. Mehata, M.C. and M. Raghuraman. 2019. Study biology and morphometric aspects of Zygogramma bicolorata Pallister (Coleoptera: Chrysomelidae) on Parthenium in Varanasi region. India Journal of Pharmacognosy and Phytochemistry. 8(2):1694-1699.

11. Mishra, K.K. 1991. Parthenium hysterophorus L. A new record for Nepal. Journal of Bombay Naural History Society. 88: 466-467.

12. Pandey, S., B.D. Joshi and L.D. Tiwari. 2001. The incidence and biology of Mexican beetle Zygogramma bicolorata Pallister (Coleoptera: Chrysomelidae) on Parthenium hysterophorus L. (Asteraceae) from Haridwar and surrounding areas. Journal of Entomological Research. 25(2): 145-149.

13. Rathod, P.N., R.O. Deotale, P.N. Dawane and
M.M. Deulkar. 2012. Biology and feeding potential of Zygogramma bicolorata Pall. on Parthenium hysterophorus Linn. on different weeds and sunflower. Journal of Soils and Crops. 22(1): 122-128.

14. Shrestha, B.B., A. Poudel, J. KC, D. Karki, R.D. Gautam and P.K. Jha. 2010. Fortuitous biological control of Parthenium hysterophorus by Zygogramma bicolorata in Nepal. Journal of Natural History Museum. 25: 333-338.

15. Shrestha, B.B., K.B. Thapa-Magar, A. Paudel and U.B. Shrestha. 2011. Beetle on the battle: Defoliation of Parthenium hysterophorus by Zygogramma bicolorata in Kathmandu valley, Nepal. Journal of Plant Science. 8: 100-104.

16. Shrestha, B.B., K. Pokhrel, N. Paudel, S. Poudel, A. Shabbir and S.W. Adkins. 2019. Distribution of Parthenium hysterophorus and one of its biological control agents (Coleoptera: Zygogramma bicolorata) in Nepal. An International Journal of Weed Biology, Ecology and Vegetation Management. DOI: 10.1111/ wre. 12384

17. Shrestha, B.B., A. Shabbir and S.W. Adkins. 2015. Parthenium hysterophorus in Nepal: a review of its weed status and possibilities for management. An International Journal of Weed Biology Ecology and Vegetation Management. DOI: 10.1111/wre.12133

18. Siddhapara, M.R., M.B. Patel and H.V. Patel. 2012. Biology of Zygogramma bicolorata Pallister (Coleoptera: Chrysomelidae) and their feeding potential on Parthenium and sunflower. Madras Agricultural Journal. 99(10-12): 841-844.

19. Singh, S., P.K. Gill, H.S. Dhaliwal and V. Kumar. 2017. Life cycle and effectiveness of Zygogramma bicolorata Pallister (Chrysomelidae: Coleoptera) on Parthenium hysterophorus eradication. Journal of Global Agriculture and Ecology. 7(2): 60-65.

20. Sushilkumar and P. Ray. 2011. Evaluation of augmentative release of Zygogramma bicolorata Pallister (Coleoptera: Chrysomelidae) for biological control of Parthenium hysterophorus L. Crop Protection. doi:10.1016/j.cropro.2011.02.005

21. Vertak, V.D. 1968. Weed that threatens crop and grasslands in Maharashtra. Indian Farming.18: 2332. 